\title{
Phenyl Silicates with Substituted Catecholate Ligands: Synthesis, Structural Studies and Reactivity
}

\author{
Etienne Levernier ${ }^{a}$, Khaoula Jaouadi, ${ }^{\mathrm{a}, \mathrm{b}}$, Heng-Rui Zhang ${ }^{\mathrm{a}}$, Vincent Corcéa ${ }^{\mathrm{a}}$, Aurélie Bernarda ${ }^{\mathrm{a}}$, Geoffrey \\ Gontard $^{a}$, Claire Troufflard, ${ }^{a}$ Laurence Grimaud $^{b}$, Etienne Derat ${ }^{a *}$, Cyril Ollivier ${ }^{a *}$, Louis Fensterbank ${ }^{a *}$
}

Dedicated to Professor llhyong Ryu in celebration of his $70^{\text {th }}$ birthday.

\begin{abstract}
While the generation of aryl radicals by photoredox catalysis is well-documented under reductive conditions, it has remained challenging under an oxidative pathway. Because of the easy photooxidation of alkyl bis-catecholato silicates, a general study on phenyl silicates bearing substituted catecholate ligands has been achieved. The newly synthesized phenyl silicates have been fully characterized and their reactivity has been explored. It was found that thanks to the substitution of the catecholate moiety and notably with the 4-cyanocatecholato ligand, the phenyl radical could be generated and trapped. Computational studies provided a rationale for these findings.
\end{abstract}

\section{Introduction}

Alkyl bis-catecholatosilicates have recently elicited intense interest in photooxidative catalysis as valuable alkyl radical precursors in radical addition reactions, ${ }^{1}$ radical-polar crossover reactions ${ }^{2}$ as well as dual photoredox-nickel cross-couplings. ${ }^{1 \mathrm{a}, 3}$ In contrast, aryl silicates counterparts have been much less utilized. Their main use has been disclosed by DeShong in palladium catalyzed cross-coupling reactions with arylhalides ${ }^{4}$ (Scheme 1, eq. 1) and by Hashmi for cross-coupling reactions with aryldiazonium salts by gold(I) catalysis ${ }^{5}$ (Scheme 1, eq. 2).

The photooxidation of arylsilicates would be of interest for two reasons. First, the generation of aryl radicals by photoredox catalysis is well-documented under photoreductive conditions from a variety of precursors such as aryl diazoniums, ${ }^{6}$ iodoniums, ${ }^{7,8}$ sulfoniums, ${ }^{7,9}$ arylhalides, ${ }^{10}$ and also benzoyl hypohalites ${ }^{11}$ (Scheme 2). In contrast and to the best of our knowledge, only one full study was published recently by the Yoshimi group under photooxidative conditions with aryl carboxylates. ${ }^{12}$ Up to $150 \mathrm{~mol} \%$ of biphenyl (BP)/1,4-dicyanonaphthalene (DCN) as photocatalytic mixture had to be used under UV irradiation to provide moderate yields ( $50 \%)$ of aryl radical adducts. Of note also, at the occasion of a very recent study by Morofuji and Kano ${ }^{13}$ dedicated to the photooxidation of alkylsilicates bearing the hexafluorocumyl alcohol dianion ligand (Martin's ligand), a

[a] E. Levernier, K. Jaouadi, H. R. Zhang, Dr. V. Corcé, A. Bernard, G. Gontard, C. Troufflard, Dr. E. Derat, Dr. C. Ollivier, Prof. L. Fensterbank

Sorbonne Université, CNRS, Institut Parisien de Chimie Moléculaire 4 Place Jussieu, CC 229, F-75252 Paris Cedex 05, France

E-mail: etienne.derat@sorbonne-universite.fr, cyril.ollivier@sorbonne-universite.fr, louis.fensterbank@sorbonneuniversite.fr

[b] K. Jaouadi, Dr. L. Grimaud

Laboratoire de biomolécules (LBM), Département de chimie, Sorbonne Université, École normale supérieure, PSL University, CNRS, 75005 Paris, France.

Supporting information for this article is given via a link at the end of the document. single example of oxidation of the corresponding phenylsillicate gave $10 \%$ of Giese-type adduct from the phenyl radical. This underlines that the generation of aryl radicals under photooxidative conditions is highly challenging.
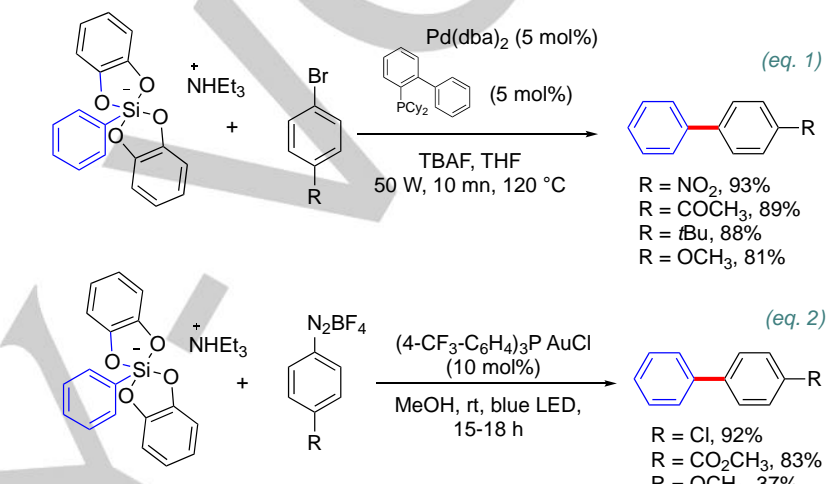

$$
\underbrace{\substack{\left(4-\mathrm{CF}_{3}-\mathrm{C}_{6} \mathrm{H}_{4}\right)_{3} \mathrm{P} \mathrm{AuCl} \\(10 \mathrm{~mol} \%)}}_{\substack{\mathrm{MeOH}, \mathrm{rt}, \text { blue LED, } \\ 15-18 \mathrm{~h}}}
$$

Scheme 1. Use of aryl silicates for $s p^{2}-s p^{2}$ cross-coupling reactions

Second, a new class of phenyl silicate derivatives could open new perspectives in terms of reactivity either in radical addition reactions or in dual catalysis. This study aimed at determining the influence of the substitution of the catecho ligands in their ability to promote the generation of aryl radicals. We therefore undertook the synthesis of various phenyl silicates and studied their structural features and reactivity.
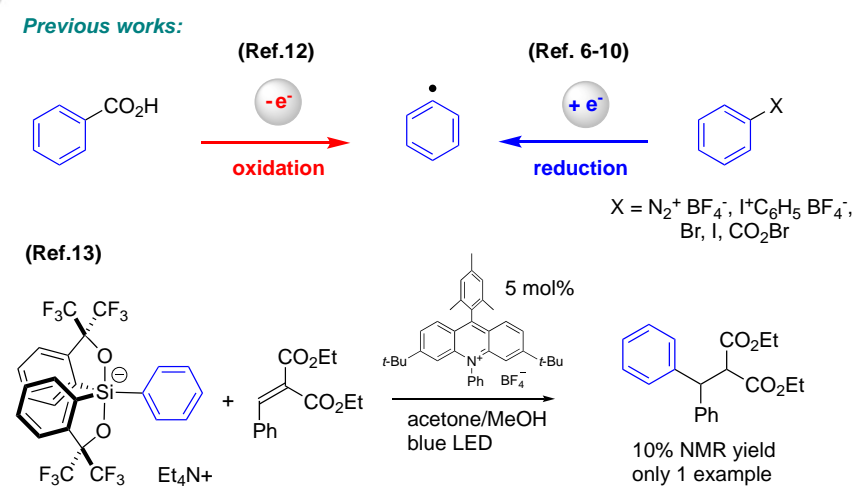

This work:

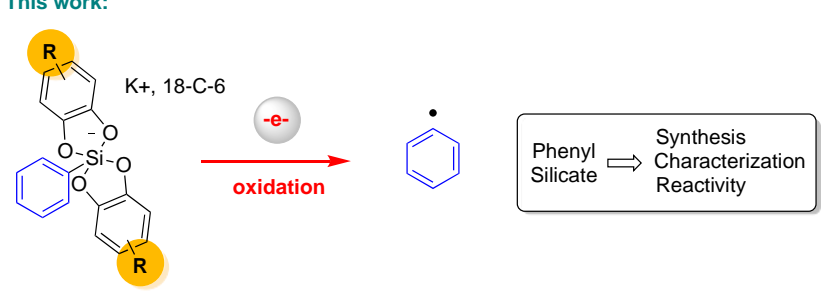

Scheme 2. Generation of aryl radicals through photocatalytic conditions 


\section{Results and Discussion}

We first focused on the reactivity of the simplest term, the phenyl bis-catecholatosilicate 1a. It was synthesized based on a previously reported protocol ${ }^{1 \mathrm{a}, 14}$ using catechol (2 equiv), 18-C-6 (1 equiv), MeOK (1 equiv) and phenyltrimethoxysilane (1 equiv). Silicate 1a was obtained in a satisfying $87 \%$ yield (reaction time: $2 \mathrm{~h}$ at room temperature, solvent of crystallization: acetone/Et ${ }_{2} \mathrm{O}$ ). Its half-wave oxidation potential in DMF was measured by cyclic voltammetry and the observed value $\left(E^{1 / 2}\right.$ ox $=+0.89 \mathrm{~V}$ vs. $\mathrm{SCE}^{1 \mathrm{a}}$ ) was compared with the reduction potential of the photocatalyst $\left[\operatorname{Ir}\left(\mathrm{dF}\left(\mathrm{CF}_{3}\right) \mathrm{ppy}\right)_{2}(\mathrm{bpy})\right] \mathrm{PF}_{6}(\mathbf{3})$ in its excited state $\left(E_{\text {red }}\left(\operatorname{Ir}(\mathrm{III})^{\star} / \operatorname{lr}(\mathrm{II})=+1.32 \mathrm{~V}\right.\right.$ vs SCE $\left.{ }^{15}\right)$. These data suggested that silicate 1a could be oxidized by this photocatalyst under irradiation. Nevertheless, all attempts to generate a phenyl radical with photocatalyst $\mathbf{3}$ and to trap it with allylsulfone $\mathbf{2}$ met limited success. Allylation product 4 was observed in only $5 \%$ yield. This finding appeared puzzling since efficient phosphorescence quenching of $\mathbf{3}$ with 1a was observed. Indeed, the quenching rate $(k q)$ constant was determined by SternVolmer analysis and found to be $k q=5.7 \times 10^{8} \mathrm{~mol}^{-1} \mathrm{~L} \mathrm{~s}^{-1}$ (in comparison to $k q=7.9 \times 10^{9} \mathrm{~mol}^{-1} \mathrm{~L} \mathrm{~s}^{-1}$ for benzyl silicate ${ }^{1 \mathrm{a}}$ ). In order to check whether this low yield was due to the instability of 1a, ${ }^{29} \mathrm{Si}$ NMR experiments were carried out before and after reaction with acceptor 2 . After 24 hours of blue LED irradiation $\left(\lambda_{\max }=450 \mathrm{~nm}\right)$ in DMF-d7, only $1 \mathrm{a}$ as silicon derivative could be detected in the mixture and no obvious degradation was also evidenced by ${ }^{1} \mathrm{H}$ NMR (Figure 1).

Additionally, when an equimolar mixture of $\mathbf{1 a}$ and $\mathbf{3}$ was irradiated under blue LED in deuterated THF as solvent, the formation of $\mathrm{C}_{6} \mathrm{H}_{5} \mathrm{D} 5$ could be observed by ${ }^{1} \mathrm{H}$ NMR $\left(\delta{ }^{1} \mathrm{H} 7.29\right.$ ppm in THF-d8) and quantified by ${ }^{2} \mathrm{H}$ NMR $\left(\delta{ }^{2} \mathrm{H} 7.35 \mathrm{ppm}\right.$ in THF-d8) to $21 \%$ NMR yield (see Scheme 3 and the supporting information for more details).

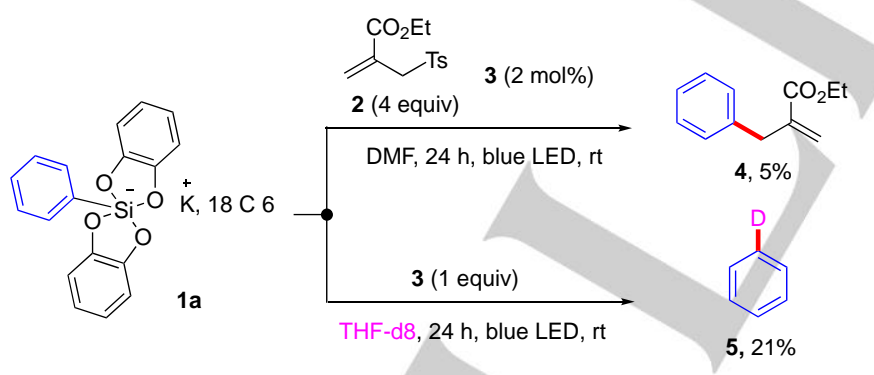

Scheme 3. Photooxidation of phenyl silicate $1 \mathrm{a}$ and phenyl radical trapping

All together, these findings suggest an inefficient oxidation process of 1a. Considering the favorable redox potentials and the efficient luminescence quenching (see above), this low reactivity of $1 \mathrm{a}$ aroused our curiosity and led us to study the role of substituents on the catechol moiety and their potential effect on the reactivity of the corresponding phenyl silicates.

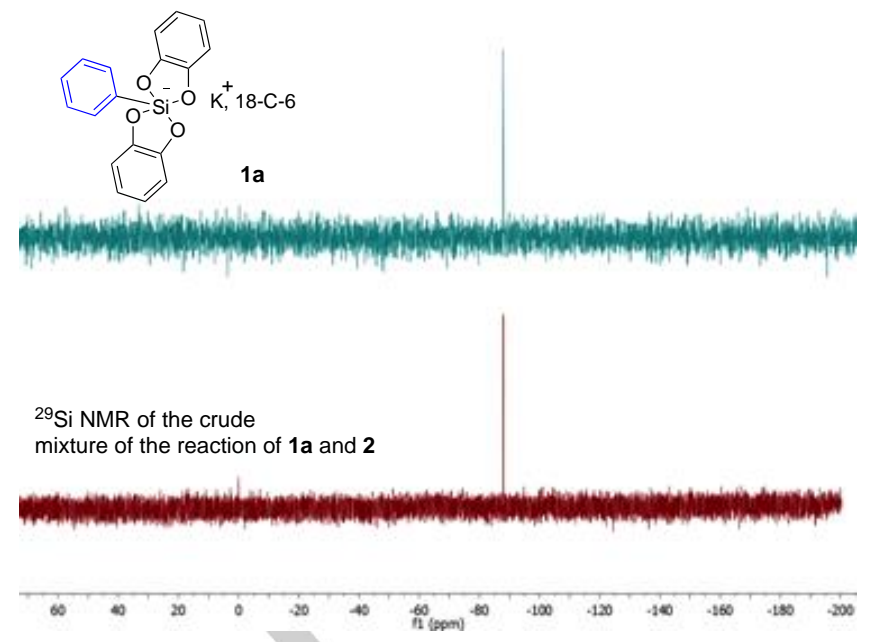

Figure 1. ${ }^{29} \mathrm{Si}$ NMR monitoring of the photocatalytic reaction of $\mathbf{1 a}$ with $\mathbf{2} \mathbf{a}$ in DMF-d7.

We first tested the putative substitution effect exerted by the catechols on the highly reactive cyclohexyl biscatecholatosilicate substrate. Notably, we wished to check that the formation of the cyclohexyl radical was still possible. Based on the previously described procedure using cyclohexyltrimethoxysilane, MeOK, 18-C-6 and catechols with diverse substitution patterns (electron donating or withdrawing groups), cyclohexylsilicates $\mathbf{6 a - 6 \mathbf { d }}$ were obtained after crystallization in acetone/ $\mathrm{Et}_{2} \mathrm{O}$ (Scheme 4). ${ }^{1 \mathrm{a}, 16}$

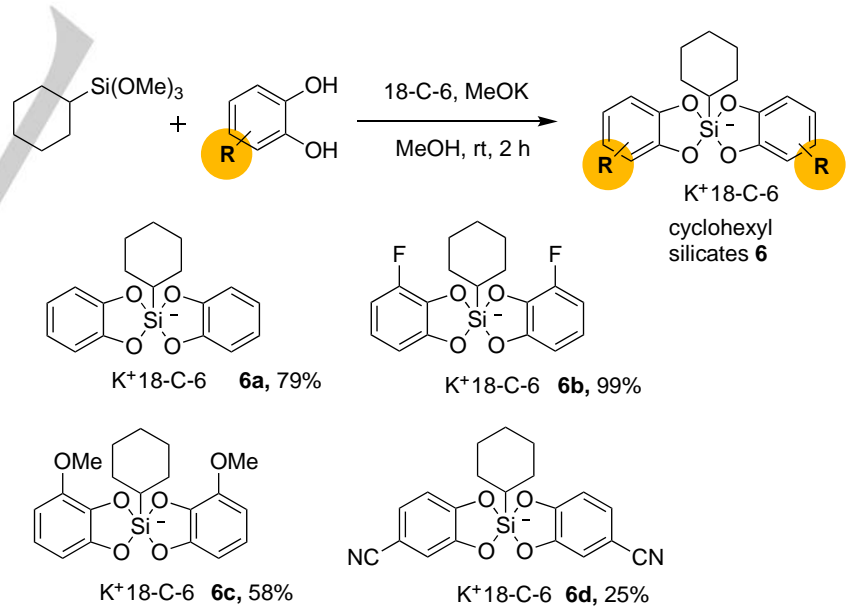

Scheme 4. Synthesis of cyclohexyl silicates 6 bearing differently substituted catechol moieties

Upon treatment with photocatalyst $\mathbf{3}$ and allylsulfone $\mathbf{2}$ under blue LED irradiation, silicates $6 \mathbf{b}\left(E_{\mathrm{ox}}{ }^{1 / 2}=+0.91 \mathrm{~V} v s \mathrm{SCE}^{17}\right)$ and $6 \mathrm{~d}\left(E_{\mathrm{ox}}{ }^{1 / 2}=+1.01 \mathrm{~V}\right)$, bearing electron withdrawing groups, afforded the corresponding radical allylation product 7 , but in slightly lower yields $(77 \%$ and $60 \%$ yields respectively) than plain silicate $6 a\left(E_{0 x}{ }^{1 / 2}=+0.69 \mathrm{~V}, 88 \%\right.$ of 7$)$ (Table 1$)$. 
Interestingly, an electron donating group such as a methoxy on the catechols $(\mathbf{6 c})$ drastically decreased the yield of this reaction and most of the starting material was recovered. In view of the lower oxidation potential of $6 \mathrm{c}\left(E_{\mathrm{ox}}{ }^{1 / 2}=+0.63 \mathrm{~V}\right)$ this result appears contradictory but was corroborated by DFT calculations (vide infra).

\begin{tabular}{|c|c|}
\hline Cyclohexyl silicate 6 & Yield of $\mathbf{7}$ (in \%) $^{1}$ \\
\hline $\mathbf{6 a}$ & 88 \\
\hline $\mathbf{6 b}$ & 77 \\
\hline $\mathbf{6 c}$ & 14 \\
\hline $\mathbf{6 d}$ & 60 \\
\hline
\end{tabular}

Table 1. Generation of cyclohexyl radical from cyclohexyl silicates 6 probed by allylation reaction

Encouraged by these results showing that the catechol substitution can modulate the reactivity of the corresponding silicates but does not prevent the photooxidation process, we prepared a library of phenyl silicates with mono- and polysubstituted catechols.

Using the same procedure as above with the appropriate catechol, most of the silicates 1 were efficiently prepared (yield > $80 \%$ ) in crystalline form suitable for X-ray diffraction analysis (Scheme 5). Thus, silicates $\mathbf{1 b}, \mathbf{1 d}$ and $\mathbf{1 h}$ bearing electron donating $(\mathrm{MeO})$ and electron withdrawing $(\mathrm{F}, \mathrm{CN})$ groups respectively were analyzed by XRD (Figure 2). ${ }^{18}$

All three crystal structures exhibit silicates in which the silicon center adopts a square pyramidal geometry, quite similar to that of 1a. Indeed, the electronic features of the catechol do not seem to have much impact on the environment of the silicon atom. $\mathbf{1 b}$ and $\mathbf{1 h}$ show a marked interaction between silicate and potassium with $\mathrm{K}-\mathrm{O}$ distances ranging from 2.7 to $3.0 \AA$, similar to previously published structures of potassium hypervalent silicates. ${ }^{1 a}$ Only 1d features weaker interactions. While the asymmetric units of $\mathbf{1 b}$ and $\mathbf{1 h}$ contain only one discrete silicate, silicate 1d shows a statistical disorder of the fluorine atoms that suggests the presence of cis and trans isomers but in undetermined proportions (see SI for more details).
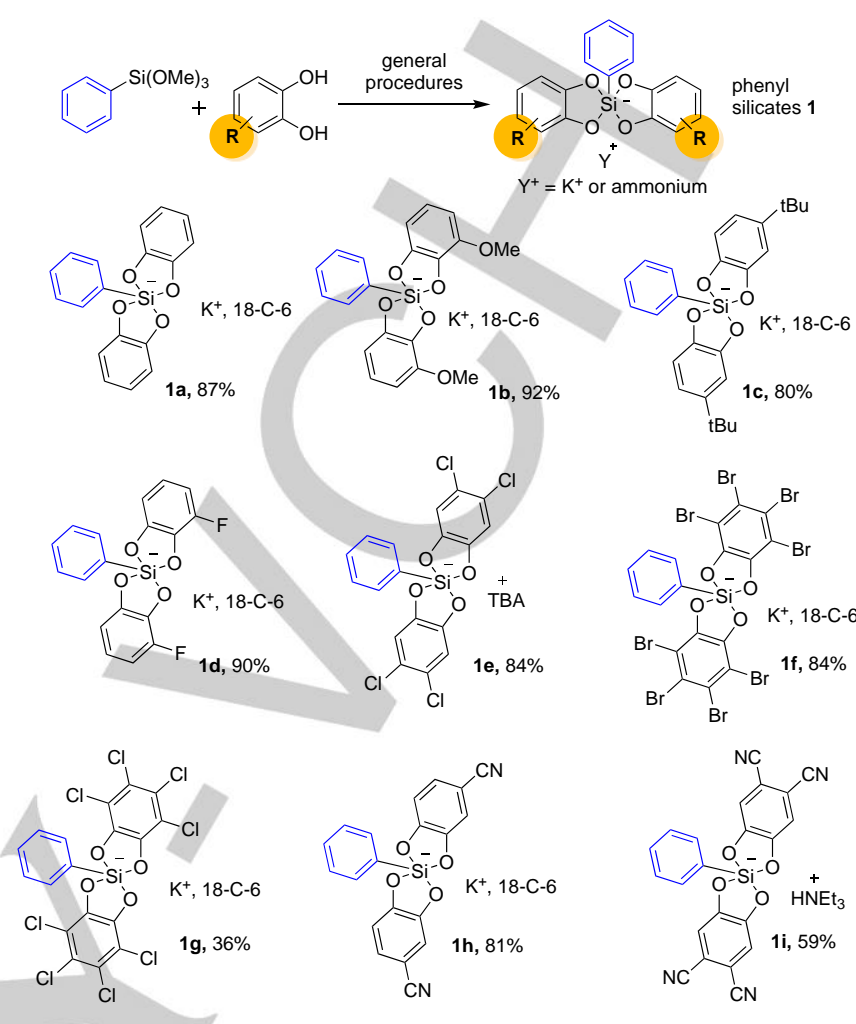

Scheme 5. Preparation of phenyl silicates 1 bearing substituted catechols

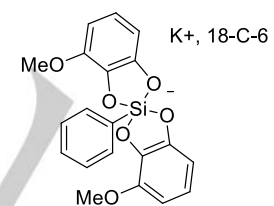

$1 \mathrm{~b}$

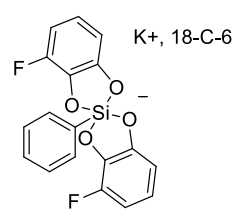

$1 d$

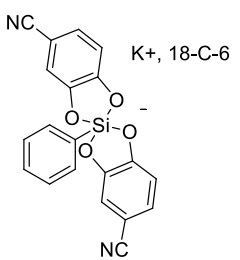

$1 \mathrm{~h}$
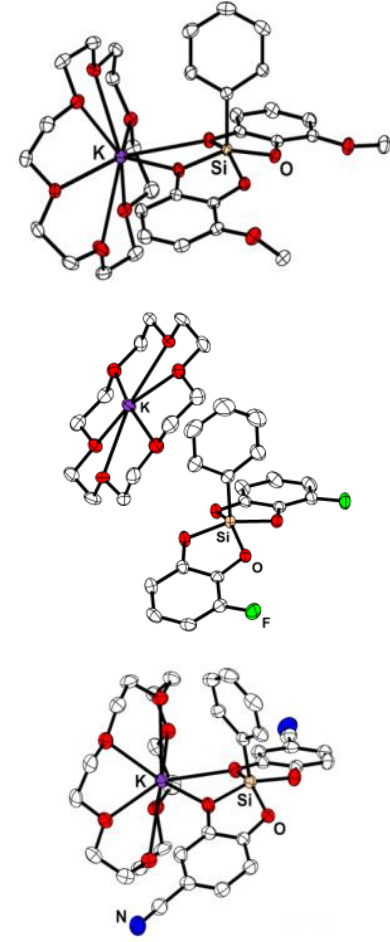

Figure 2. XRD analyses of silicates $\mathbf{1 b}, \mathbf{1 d}$ and $\mathbf{1 h}$. Only cis isomer of $\mathbf{1 d}$ depicted and hydrogens omitted for clarity. 
The presence of two isomers was also confirmed by ${ }^{13} \mathrm{C}$ NMR. All resonances of the non-symmetrical catechol moieties in ${ }^{13} \mathrm{C}$ NMR were doubled with identical integration for both species in the case of $\mathbf{1 d}$, but also for the other non-symmetrical phenylsilicates $\mathbf{1 b}, \mathbf{1 c}, \mathbf{1 h}$. It has to be mentioned that this type of 1:1 mixture of two isomers was also observed in the cyclohexyl series (silicates 6 b-d).

Intrigued by this finding, we wondered if an equilibrium exists between both cis and trans isomers in solution. To answer this question, ${ }^{13} \mathrm{C}$ NMR of $\mathbf{1 h}$ at various temperatures was conducted (in acetone-d6 at low temperature (below $273 \mathrm{~K}$ ) and DMSO-d6 at higher temperature (from $303 \mathrm{~K}$ ), Figure 3). ${ }^{19}$

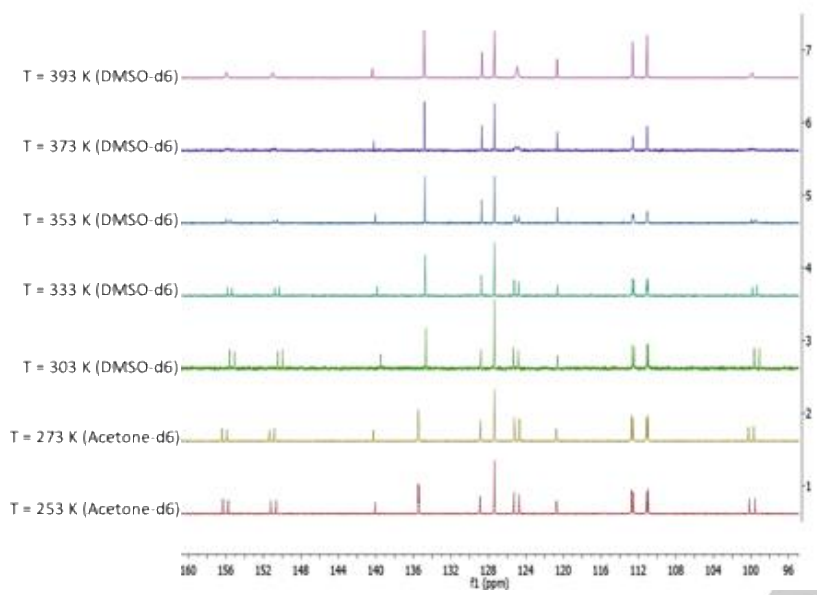

Figure $3 .{ }^{13} \mathrm{C}$ NMR of silicate $\mathbf{1 h}$ at various temperatures

A coalescence of the peaks was observed above $333 \mathrm{~K}$ probably due to Berry pseudo-rotation ${ }^{20}$ suggesting that an equilibrium exists between the two isomers. DFT calculations also indicated that the energetic gap between the cis and trans form for $\mathbf{1 b}$ is $3.3 \mathrm{kcal} / \mathrm{mol}$ in favor of the cis form. For $\mathbf{1 h}$, the trans form is slightly favored by $0.6 \mathrm{kcal} / \mathrm{mol}$.

After studying the structural features of these new silicon derivatives, we examined other key properties. First, UV-vis absorption spectra were recorded. All silicates 1 exhibited a unique absorption band spanning from $276 \mathrm{~nm}$ for $1 \mathbf{d}$ to $303 \mathrm{~nm}$ for 1g. Importantly, whatever the substitution pattern, no noticeable absorption was observed in the wavelength range of blue LED, previously used for the photooxidation of alkyl silicates (from 400 to $520 \mathrm{~nm}$ ) (see Figure 4 and the supporting information for more details and UV data).

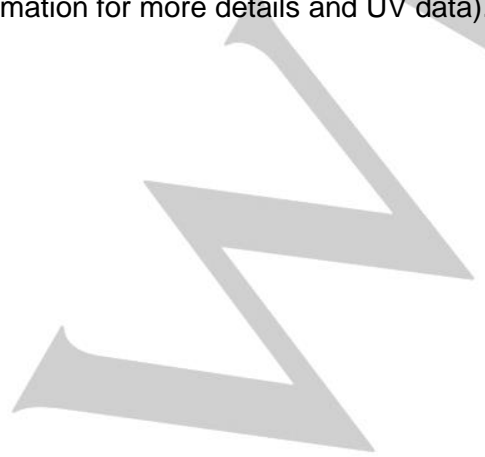

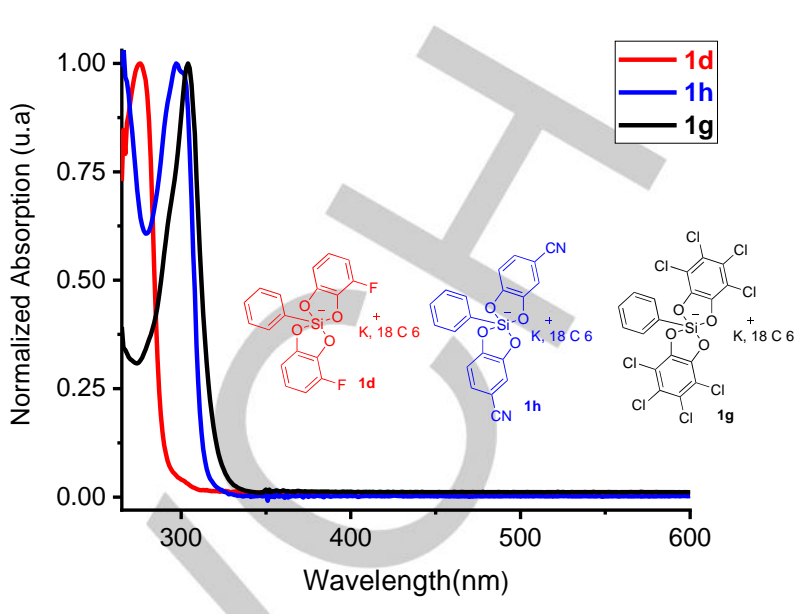

Figure 4. Absorption spectra of silicates $1 \mathrm{~b}, \mathbf{1 d}$ and $\mathbf{1 h}$

Second, the oxidation potentials of silicates 1a-i were measured in DMF as displayed in Table 2.

\begin{tabular}{|c|c|}
\hline Silicate & $E_{\text {ox }}{ }^{1 / 2}$ (vs SCE in DMF) \\
\hline $\mathbf{1 a}$ & $+0.89 \mathrm{~V}$ \\
\hline $\mathbf{1 b}$ & $+0.81 \mathrm{~V}$ \\
\hline $\mathbf{1 c}$ & $+1.09 \mathrm{~V}$ \\
\hline $\mathbf{1 d}$ & $+1.05 \mathrm{~V}$ \\
\hline $\mathbf{1 e}$ & $+1.13 \mathrm{~V}$ \\
\hline $\mathbf{1 f}$ & $+1.46 \mathrm{~V}$ \\
\hline $\mathbf{1 g}$ & $+1.37 \mathrm{~V}$ \\
\hline $\mathbf{1 h}$ & $+1.33 \mathrm{~V}$ \\
\hline $\mathbf{1 i}$ & $+1.62 \mathrm{~V}$ \\
\hline
\end{tabular}

Table 2. Half-wave oxidation potentials of silicates 1a-i

Interestingly, catechol modifications resulted in important variations of the oxidation potentials, from $E_{0 x}{ }^{1 / 2}=+0.81 \mathrm{~V}$ for 1b to $E_{\mathrm{ox}}{ }^{1 / 2}=+1.62 \mathrm{~V}$ for $1 \mathrm{i}$ with $E_{\mathrm{ox}}{ }^{1 / 2}=+0.89 \mathrm{~V}$ for the unsubstituted phenylsilicate 1a. Thus, a donating group on the catechols as for $\mathbf{1 b}$ was found to logically decrease the oxidation potential while electron withdrawing groups significantly increased the values above $+1.0 \mathrm{~V}\left(E_{0 x}{ }^{1 / 2}=+1.05 \mathrm{~V}\right.$ for $\left.1 \mathrm{~d}\right) .^{21}$ Higher oxidation potentials could even be reached by using the per-bromocatechol or by adding two cyano groups $\left(E_{\mathrm{ox}}{ }^{1 / 2}(\mathbf{1 f})=+\right.$ $1.46 \mathrm{~V}$ and $\left.E_{\mathrm{ox}}{ }^{1 / 2}(\mathbf{1 f})=+1.62 \mathrm{~V}\right)$. Even if the oxidation of $\mathbf{1 f}$ and $\mathbf{1 i}$ by the photoactivated $\mathbf{3} \quad\left[\operatorname{Ir}\left(\mathrm{dF}\left(\mathrm{CF}_{3}\right) \text { ppy }\right)_{2}-(\mathrm{bpy})\right] \mathrm{PF}_{6}$ $\left(E_{\text {red }}\left(\operatorname{Ir}(\mathrm{III})^{*} / \operatorname{Ir}(\mathrm{II})=+1.32 \mathrm{~V}\right)\right.$ appeared difficult, all the other silicates 1 could potentially lead to the generation of the phenyl radical. Thus, we proceeded this study with the photocatalytic allylation reaction from silicates 1a-i with allylsulfone 2 in the presence of $2 \mathrm{~mol} \%$ of $\mathbf{3}$. Results are summarized in Table $\mathbf{3}$.

Although a yield $<10 \%$ was obtained from silicates 1a-e and 1i, silicate $\mathbf{1 h}$ bearing a cyano group on the catechol afforded 4 in $35 \%$ yield. Per-brominated and per-chlorinated catechols 1 ff 
and $\mathbf{1 g}$ also provided the desired product 4 in slightly better yields than silicate $1 \mathrm{a}$ ( $15 \%$ and $23 \%$ respectively). Nevertheless these yields are still lower than the one obtained with silicate $\mathbf{1 h}$. The higher oxidation potentials of $\mathbf{1 f}$ and $\mathbf{1 g}$ in comparison to $\mathbf{1 h}$ might explain this result. Also, as previously observed in Table 1 with cyclohexyl silicates, the methoxy substitution was found to be detrimental resulting in a decreased yield. Thus, the modification of the catechol moiety proved to modulate the reactivity of the phenyl silicates 1 in the photocatalytic allylation type reaction.

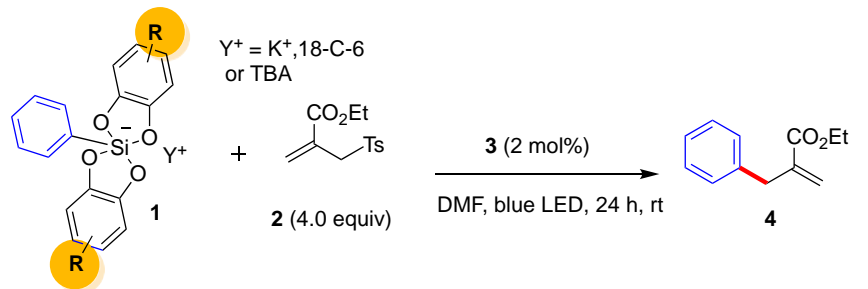

\begin{tabular}{|c|c|}
\hline Silicate 1 & Yield of 4 (in \%) ${ }^{1}$ \\
\hline $1 \mathrm{a}$ & $5 \%$ \\
\hline $1 b$ & $9 \%$ \\
\hline 1c & $8 \%$ \\
\hline 1d & $6 \%$ \\
\hline $1 e$ & $6 \%$ \\
\hline $1 f$ & $15 \%$ \\
\hline $1 \mathrm{~g}$ & $23 \%$ \\
\hline $1 \mathrm{~h}$ & $35 \%$ \\
\hline $1 \mathrm{i}$ & $7 \%$ \\
\hline
\end{tabular}

Table 3. Photocatalytic allylation reaction of phenylsilicates1

Encouraged by these results, we optimized the reaction of the most promising silicate $1 \mathrm{~h}$ with acceptor 2 (Table 4). The influence of different counterions (ammoniums and potassium with and without 18-C-6, entries 6, 11 and 12) was studied but no significant improvement was observed. The temperature (room temperature or $100^{\circ} \mathrm{C}$, entries 5 and 6 ) did not affect the reaction efficiency. Switching to some organic photocatalysts resulted in a decreased yield (entries 1, 2 and 3) ${ }^{22,23}$ Even the very oxidizing Fukuzumi's acridinium $\left(E_{\text {red }}\left(\mathrm{PC}^{*} / \mathrm{PC}^{*}\right)=+2.06 \mathrm{~V}\right.$ vs $\mathrm{SCE}^{24}$ ) did not afford 4 in a better yield. These results are consistent with what was previously observed with alkylsilicates. ${ }^{25}$ Different solvents (DMF, DMSO, MeCN, EtOH), reaction times and concentrations were also screened but, despite all our efforts, the yield remained modest. Notably, prolonged reaction times did not result in significant improvements (entry 6 vs entries 9 and 10). Hence, the best conditions were found to be in DMSO with $\mathbf{3}$ at room temperature for $24 \mathrm{~h}(40 \%$, entry 4$)$. Some control experiments were also carried out. The reaction in the dark or photocatalyst free conditions did not afford any product (entries 7 and 8). Therefore, the presence of a photocatalyst under irradiation is mandatory to generate the phenyl radical.

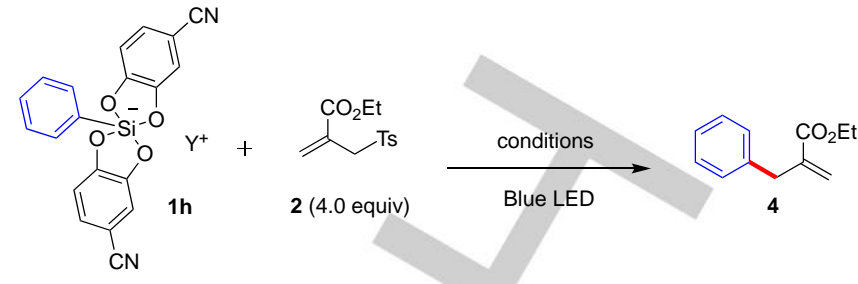

\begin{tabular}{|c|c|c|c|c|c|c|}
\hline Entry & Solvent & $\mathbf{T}$ & Photocatalyst & $t$ & $\mathrm{Y}^{+}$ & $\begin{array}{l}\text { Yield } \\
\text { of } 4^{1}\end{array}$ \\
\hline 1 & DMF & rt & $\begin{array}{l}\text { Fukuzumi's } \\
\text { acridinium }\end{array}$ & $24 \mathrm{~h}$ & $\begin{array}{c}\mathrm{K}^{+} / 18- \\
\mathrm{C}-6\end{array}$ & $6 \%$ \\
\hline 2 & DMF & rt & Pyrylium salt $^{2}$ & $24 \mathrm{~h}$ & $\begin{array}{c}\mathrm{K}^{+} / 18- \\
\mathrm{C}-6\end{array}$ & $7 \%$ \\
\hline 3 & DMF & $\mathrm{rt}$ & 4CzIPN & $24 \mathrm{~h}$ & $\begin{array}{c}\mathrm{K}^{+} \mathrm{I} \\
18-\mathrm{C}-6\end{array}$ & $7 \%$ \\
\hline 4 & DMSO & $\mathrm{rt}$ & 3 & $24 \mathrm{~h}$ & $\begin{array}{c}\mathrm{K}^{+} / \\
18-\mathrm{C}-6\end{array}$ & $40 \%$ \\
\hline 5 & DMF & $100^{\circ} \mathrm{C}$ & 3 & $24 \mathrm{~h}$ & $\begin{array}{c}\mathrm{K}^{+} \mathrm{I} \\
18-\mathrm{C}-6 \\
\end{array}$ & $38 \%$ \\
\hline 6 & DMF & $\mathrm{rt}$ & 3 & $24 \mathrm{~h}$ & $\begin{array}{c}\mathrm{K}^{+} / \\
18-\mathrm{C}-6\end{array}$ & $35 \%$ \\
\hline 7 & DMF & rt & - & $24 \mathrm{~h}$ & $\begin{array}{c}\mathrm{K}^{+} \mathrm{I} \\
18-\mathrm{C}-6\end{array}$ & $0 \%$ \\
\hline 8 & DMF & rt & 3 & $24 \mathrm{~h}$ & $\begin{array}{c}\mathrm{K}^{+} / \\
18-\mathrm{C}-6\end{array}$ & $0 \%{ }^{3}$ \\
\hline 9 & DMF & rt & 3 & $68 \mathrm{~h}$ & $\begin{array}{c}\mathrm{K}^{+} / \\
18-\mathrm{C}-6\end{array}$ & $35 \%$ \\
\hline 10 & DMF & rt & 3 & $68 \mathrm{~h}$ & $\begin{array}{c}\mathrm{K}^{+} / \\
18-\mathrm{C}-6 \\
\end{array}$ & $41 \%^{4}$ \\
\hline 11 & DMF & rt & 3 & $24 \mathrm{~h}$ & $\mathrm{~K}^{+}$ & $30 \%$ \\
\hline 12 & DMF & rt & 3 & $24 \mathrm{~h}$ & $\mathrm{Et}_{3} \mathrm{NH}^{+}$ & $35 \%$ \\
\hline 13 & $\mathrm{CH}_{3} \mathrm{CN}$ & $\mathrm{rt}$ & 3 & $24 \mathrm{~h}$ & $\mathrm{TBA}^{+}$ & $0 \%$ \\
\hline 14 & $\mathrm{EtOH}$ & rt & 3 & $24 \mathrm{~h}$ & $\mathrm{TBA}^{+}$ & $20 \%$ \\
\hline 15 & DMSO & rt & 3 & $24 \mathrm{~h}$ & $\mathrm{TBA}^{+}$ & $35 \%$ \\
\hline 16 & DMF & rt & $3^{5}$ & $24 \mathrm{~h}$ & $\begin{array}{c}\mathrm{K}^{+} / \\
18-\mathrm{C}-6\end{array}$ & $40 \%$ \\
\hline
\end{tabular}

${ }^{1}$ [Silicate] $=0.1$ mol. ${ }^{-1}, 3(2 \mathrm{~mol} \%),{ }^{1} \mathrm{H}$ NMR yield of 4 using $1,3,5$ trimethoxybenzene as NMR standard; ${ }^{2} 2,4,6$-tri $\left(p\right.$-tolyl)pyrylium tetrafluoroborate salt; ${ }^{3}$ reaction in the dark; ${ }^{4}$ [Silicate $]=0.2 \mathrm{~mol} . \mathrm{L}^{-1} ;{ }^{5} \mathbf{3}(10 \mathrm{~mol} \%)$

Table 4. Optimization of the allylation reaction

Inspired by the pioneering work of Nishigaichi showing that silicates bearing catechol or 2,3-hydroxynaphthalene ligands can be photoactivated by direct irradiation, ${ }^{26}$ the photo allylation reaction of silicate $\mathbf{1 h}$ was also tested at $300 \mathrm{~nm}$ with and without 3 but limited success was met since only $10 \%$ and $6 \%$ of product $\mathbf{4}$ were isolated respectively. So, even if this silicate absorbs UV-B light, the use of $\mathbf{3}$ as photocatalyst under blue LED irradiation remains more efficient. This was further corroborated by the fact that the phosphorescence quenching of $\mathbf{3}$ with silicate $\mathbf{1 h}$ was also observed and thanks to a SternVolmer plot, a quenching constant of $1.31 \times 10^{8} \mathrm{~mol}^{-1} \mathrm{~L} \mathrm{~s}^{-1}$ was obtained (compared to $5.7 \times 10^{8} \mathrm{~mol}^{-1} \mathrm{~L} \mathrm{~s}^{-1}$ for silicate 1a). Thus, silicate $1 \mathrm{~h}$ does not quench the iridium photocatalyst more efficiently than silicate 1a (Figure 5).

D-abstraction from deuterated THF-d8 was also probed and led to the formation of $\mathrm{C}_{6} \mathrm{H}_{5} \mathrm{D}$ in $51 \%$ yield (as quantified by ${ }^{2} \mathrm{H}$ NMR) from $\mathbf{1 h}$, in comparison to $21 \%$ yield obtained with 
unsubstituted silicate 1a (see above) confirming the effect of the catecholate substitution. ${ }^{27}$

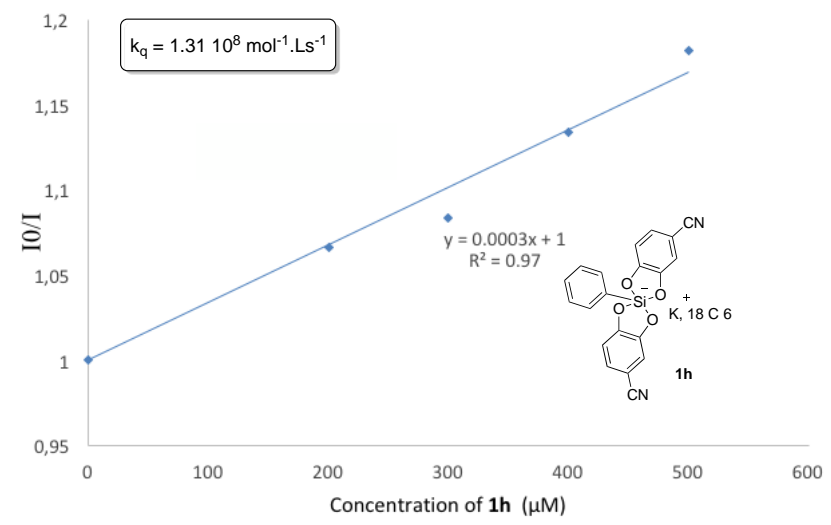

Figure 5. Stern-Volmer plot - quench of silicate $\mathbf{1 h}$ and $\mathbf{3}$

To better understand the difference of reactivity between alkylsilicates and phenyl silicates, we resorted to computational studies. The fragmentation of the intermediate hypercoordinated radical resulting from the oxidation by the photocatalyst was assessed for both types of silicates. Energy barriers for the cleavage of the silicon-carbon bond and the free energy of the reaction are summarized in Table 5, in the presence or absence of DMF as coordinating ligand on the silicon center. In all cases, it was found that the presence of DMF reduces the barrier of radical expulsion. With DMF, the generation of a primary alkyl radical is rather easy with an energy barrier of $17.45 \mathrm{kcal} / \mathrm{mol}$, which explains why various transformations have been observed with this type of substrates. ${ }^{1,3}$ For cyclohexyl silicates, we observe a consistent and slightly lower barrier of $13.23 \mathrm{kcal} / \mathrm{mol}$ to expel the cyclohexyl radical from $\mathbf{I} \cdot \mathbf{C y}$. Adding cyano groups helps to reduce this barrier $\left(\mathbf{I} \cdot \mathbf{C} \cdot{ }^{\circ} \mathbf{C N} \rightarrow\|\cdot\|^{\circ} \mathbf{C y} \cdot \mathbf{C N}\right)$ to 10.51 $\mathrm{kcal} / \mathrm{mol}$. Interestingly, methoxy groups on $\mathbf{l} \cdot \mathrm{Cy} \cdot \mathrm{OMe}$ resulted in a much higher calculated barrier $(37.73 \mathrm{kcal} / \mathrm{mol})$ that is corroborated by the poor reactivity of $6 \mathbf{c}$ in an allylation reaction (see Table 1). Calculations also featured a distinct scenario for this silicate. While in the other cases, upon departure of the radical, the DMF strongly interacts with the silicon center of the generated bis-catecholato spirosilane to give a square pyramid hypercoordinated silicon species, $\| \cdot C y \cdot O M e$ fragments differently and the resulting methoxy substituted bis-catecholato spirosilane adopts a tetrahedral shape with no coordination of the DMF. The electron donation of the methoxy groups presumably disfavors the formation of the hypercoordinated species.

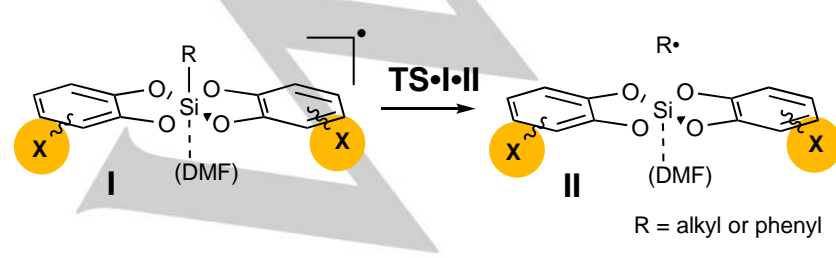

\begin{tabular}{|l|c|c|}
\hline & $\begin{array}{c}\text { Free } \\
\text { Barrier } \\
\text { (kcal/mol) }\end{array}$ & $\begin{array}{c}\text { Fergy of } \\
\text { eneaction } \\
\text { (kcal/mol) }\end{array}$ \\
\hline & & \\
\hline
\end{tabular}

Table 5. Barrier and Gibbs free energy of the reaction (in $\mathrm{kcal} / \mathrm{mol}$ ) corresponding to radical formation for various oxidized silicates, as calculated at the wB97M-D3BJ/def2-SV(P) level. Values in parentheses correspond to calculations done without DMF.

Importantly, the calculations also supported that phenylsilicates 1 are less prone to expel a radical upon oxidation. Without any substituent on the catechol moiety, the energy 
barrier was calculated to be $27.46 \mathrm{kcal} / \mathrm{mol}$ and the generated intermediate radical is rather unstable (with a Gibbs free energy of $22 \mathrm{kcal} / \mathrm{mol}$ ). ${ }^{28}$ One should also notice that the expelled phenyl radical on $\| \cdot P h$ and analogs interacts through $\pi-\pi$ interactions with one of the catechol moieties. Thus, the interaction distances between centroids relevant for this $\pi$ stacking interaction are respectively $3.21 \AA$, $3.23 \AA$ and $3.12 \AA$ for $\|\cdot \mathbf{P h},\| \cdot \mathbf{P h} \cdot \mathbf{C N}, \| \cdot \mathbf{P h} \cdot \mathrm{OMe}$. This marks a sharp contrast with the expelled alkyl radicals that do not interact at all with the catechol ligands and are less bound to the silicon entity. Finally, the situation proved to be different with the experimentally more reactive silicate $\mathbf{1 h}$ since the energy barrier to generate the radical was about $19 \mathrm{kcal} / \mathrm{mol}(\mathbf{I} \cdot \mathbf{P h} \cdot \mathbf{C N})$, thus far more accessible. Nevertheless, the radical is still rather unstable with a highly endergonic process of $19 \mathrm{kcal} / \mathrm{mol}(\mathbf{l} \cdot \mathbf{P h} \cdot \mathbf{C N} \rightarrow \| \cdot \mathbf{P h} \cdot \mathbf{C N})$ Finally, the high barrier for $1 \cdot P h \cdot O M e ~(>40 \mathrm{kcal} / \mathrm{mol})$ is consistent with what was found for $1 \cdot \mathbf{C y} \cdot \mathbf{O M e}$. These results prompted us to investigate the electronic structure of these radicals more in detail (Figure 6)
To our surprise, these radicals are not classical and do not follow the Aufbau principle. Indeed, for most of the radicals, the orbital encompassing the unpaired electron corresponds to the highest occupied molecular orbital (HOMO). Here, the orbital better suited to describe the calculated spin density is not the HOMO but a lower lying molecular orbital. This phenomenon is known as SOMO-HOMO inversion and has been previously described for various systems, but it has never been invoked for hypervalent species. ${ }^{29}$ The frontier orbitals, as well as the spin density, are depicted in Figures 6 and 7 for radicals $\| \cdot P h$ and $\| \cdot \mathbf{P h} \cdot \mathbf{C N}$ originating from $\mathbf{1 a}$ and $\mathbf{1 h}$. It can be observed that, in the case of the radical species $\| \cdot \mathbf{P h} \cdot \mathbf{C N}$, the SOMO is lower in energy $(-9.10 \mathrm{eV})$ than for the non-substituted catechol radical species $(-8.63 \mathrm{eV})$. Overall, these findings could rationalize why the $\mathrm{CN}$ substituted silicate $\mathbf{1 h}$ behaves differently from the unsubstituted species 1a. First, the barrier for radical extrusion is weaker $(27.46 \mathrm{kcal} / \mathrm{mol}$ for $1 \cdot P h$ vs. $18.99 \mathrm{kcal} / \mathrm{mol}$ for $1 \cdot P h \cdot C N)$ allowing an easier generation of the phenyl radical. In the case of $\| \cdot \cdot P h \cdot C N$, the extra stability of the radical $(-9.10 \mathrm{eV}$ vs. -8.63 $\mathrm{eV})$ would result in an optimized radical reactivity with presumably less side reactions.

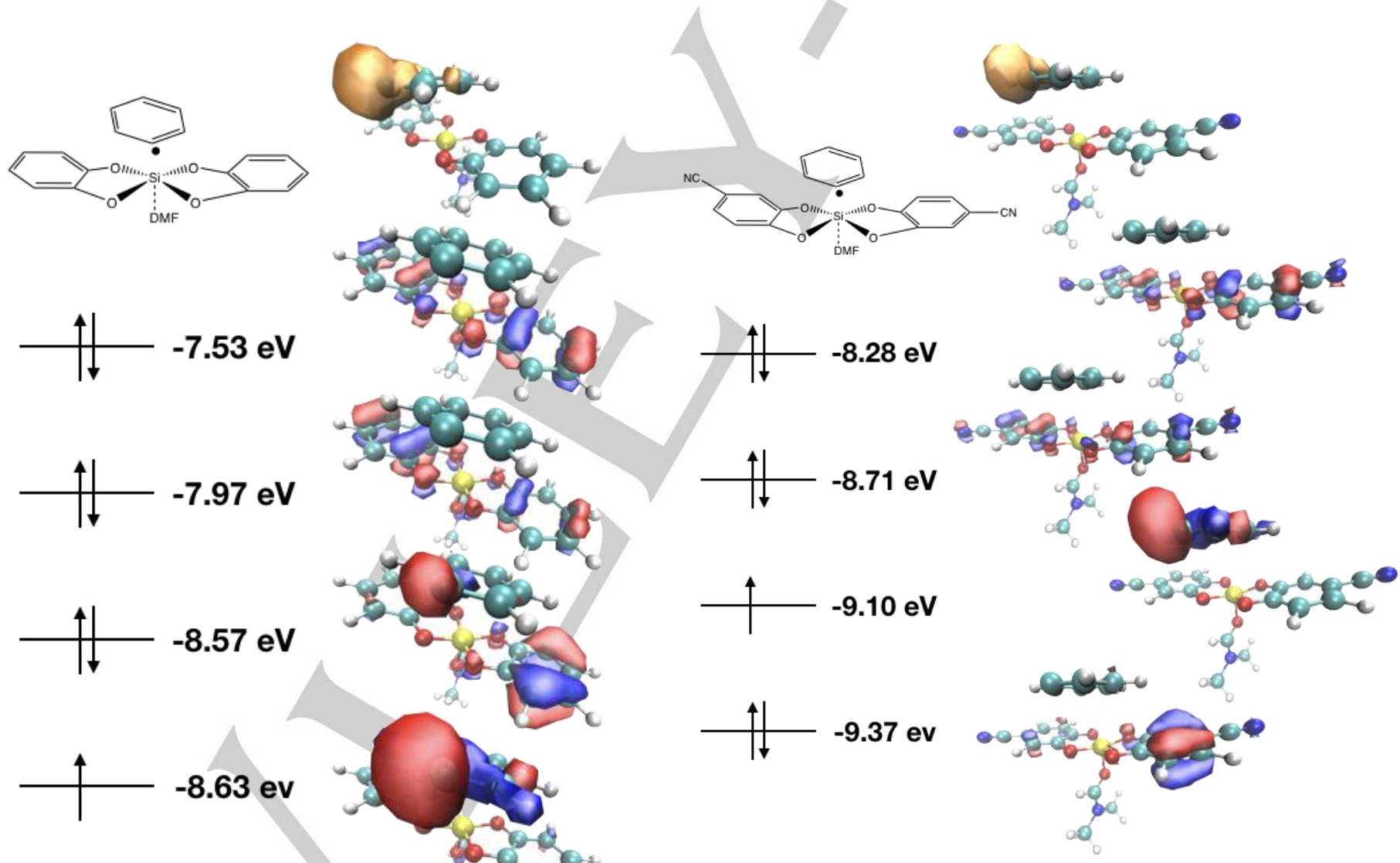

Figure 7. Spin density and frontier orbitals diagram for the oxidized phenylsilicate $\| \mathbf{P h} \cdot \mathbf{C N}$

Figure 6. Spin density and frontier orbitals diagram for the oxidized aryl silicate $\| \cdot P h$ 


\section{Conclusions}

In this study, we have synthesized and fully characterized by NMR, UV-vis absorption, X-ray diffraction and cyclic voltammetry a series of phenyl bis-catecholatosilicate derivatives $\mathbf{1}$ featuring electronic modulation on the catechol ligand. While they share a lot of common features with their alkylsilicate congeners, a notable difference with these compounds resides in their higher oxidation potentials that generally lay above $1.0 \mathrm{~V}$ vs SCE, except for the unsubstituted phenylsilicate 1a or the methoxy substituted one $\mathbf{1 b}$, and bode for a less favorable oxidation. The study of their photooxidation gave average results from a synthetic point of view but revealed for the first time an important effect of the catechol substitution. Counter-intuitively, phenyl silicates with the most donor substituents on catechol, and therefore with the lowest oxidation potentials, did not give the best results. It is the 4-cyanocatecholato ligand (silicate $\mathbf{1 h}$ ) which provided the best results and led to about $40 \%$ of allylation of the phenyl radical. Although modest, these yields should be understood in a context where the generation of aryl radicals by oxidative photoredox catalysis is hardly described. DFT calculations have allowed to rationalize the different observations and have highlighted an intriguing SOMO-HOMO inversion that has never been described for hypervalent species. These results also emphasize that silicates should be considered as first-rate precursors to challenging radicals.

\section{Experimental Section}

\section{General procedure for conjugate addition:}

To a dried Schlenk flask were added the appropriate silicate (1.0 equiv), 3 (2 mol \%) and the allyl sulfone (4 equiv). The Schlenk flask was sealed with a rubber septum and evacuated / purged with vacuum / argon three times. Then degassed solvent $(0.1 \mathrm{M})$ was introduced and the reaction mixture was irradiated with blue LED $(477 \mathrm{~nm})$ at room temperature for $24 \mathrm{~h}$ under an argon atmosphere. The reaction mixture was diluted with diethyl ether, washed with water (2 times), dried over $\mathrm{MgSO}_{4}$ and evaporated under reduced pressure. The crude residue was analyzed by ${ }^{1} \mathrm{H}$ NMR (with 1equiv of 1,3,5-trimethoxybenzene as NMR standard).

\section{Acknowledgements}

We thank Sorbonne Université, PSL University, CNRS, ANR-17CE07-0018 HyperSilight ( $\mathrm{PhD}$ grant to $\mathrm{EL}$ and $\mathrm{KJ}$ ), the Chinese Scholarship Council ( $\mathrm{PhD}$ grant to $\mathrm{HZ}$ ) for financial support and Alexandre Millanvois for the graphical abstract.

Keywords: photoredox catalysis, aryl radical, silicate, oxidation
[1] a) V. Corcé, L.-M. Chamoreau, E. Derat, J.-P. Goddard, C. Ollivier, L. Fensterbank, Angew. Chem. Int. Ed. 2015, 54, 11414-11418; Angew. Chem. 2015, 127, 11576-11580; b) A. Cartier, E. Levernier, V. Corcé, T. Fukuyama, A.-L. Dhimane, C. Ollivier, I. Ryu, L. Fensterbank, Angew. Chem. Int. Ed. 2019, 58, 1789-1793; Angew. Chem. Int. Ed. 2019, 131, 1803-1807; c) A. Cartier, E. Levernier, A.-L. Dhimane, T. Fukuyama, C. Ollivier, I. Ryu, L. Fensterbank, Adv. Synth. Catal. 2020, 362, 22542259; d) N. R. Patel, C. B. Kelly, A. P. Siegenfeld, G. A. Molander, ACS Catal. 2017, 7, 1766-1770; e) S. T. J. Cullen, G. F. Friestad, Org. Lett. 2019, 21, 8290-8294.

[2] a) S. B. Lang, R. J. Wiles, C. B. Kelly, G. A. Molander, Angew.Chem.Int. Ed. 2017, 56, 15073-15077; Angew. Chem. 2017,129,15269-15273; b) J. P. Phelan, S. B. Lang, J. S. Compton, C. B. Kelly, R. Dykstra, O. Gutierrez, G. A. Molander, J. Am. Chem. Soc. 2018, 140, 8037-8047; c) T. Guo, L. Zhang, X. Liu, Y. Fang, X. Jin, Y. Yang, Y. Li, B. Chen, M. Ouyang, Adv. Synth. Catal. 2018, 360, 4459-4463; d) L. R. E. Pantaine, J. A. Milligan, J. K. Matsui, C. B. Kelly, G. A. Molander, Org. Lett. 2019, 21, 2317-2321

[3] a) C. Lévêque, L. Chennenberg, V. Corcé, J.-P. Goddard, C. Ollivier, L. Fensterbank, Org. Chem. Front. 2016, 3, 462-465; b) E. Levernier, V. Corcé, L.-M. Rakotoarison, A. Smith, M. Zhang, S. Ognier, M Tatoulian, C. Ollivier, L. Fensterbank, Org. Chem. Front. 2019, 6, 13781382; c) M. Jouffroy, D. N. Primer, G. A. Molander, J. Am. Chem. Soc. 2016, 138, 475-478; d) N. R. Patel, C. B. Kelly, M. Jouffroy and G. A. Molander, Org. Lett. 2016, 18, 764-767; e) M. Jouffroy, C. B. Kelly, G. A. Molander, Org. Lett. 2016, 18, 876-879; f) J. P. Phelan, S. B. Lang, J. Sim, S. Berritt, A. K. Peat, K. Billings, L. Fan, G. A. Molander, J. Am. Chem. Soc. 2019, 141, 3723-3732; g) J. K. Matsui, S. B. Lang, D. R. Heitz, G. A. Molander, ACS Catal. 2017, 7, 2563-2575; h) K. Lin, R. J. Wiles, C. B. Kelly, G. H. M. Davies, G. A. Molander, ACS. Catal. 2017, 7, 5129-5133; i) B. A. Vara, X. Li, S. Berritt. C. R. Walters, E. J. Petersson, G. A. Molander, Chem. Sci. 2018, 9, 336-344; j) S. O. Badir, J. Sim, K. Billings, A. Csakai, X. Zhang, W. Dong, G. A. Molander, Org. Lett. 2020, 22, 1046-1051; k) K. D. Raynor, G. D. May, U. K. Bandarage, M. J. Boyd, J. Org. Chem. 2018, 83, 1551-1557.

[4] a) W. M. Seganish, P. DeShong, J. Org. Chem. 2004, 69, 1137-1143; b) W. M. Seganish, P. DeShong, Org. Lett. 2004, 5, 4379-4381.

[5] S. Witzel, K. Sekine, M. Rudolf, S. K. Hashmi, Chem. Commun. 2018, 54, 13802-13804.

[6] For a general revue on radical precursor in reduction see: I. Ghosh, L. Marzo, A. Das, R. Shaikh, B. König, Acc. Chem. Res. 2016, 49, 15661577; For a revue on diazoniums see: F. Mo, G. Dong, Y. Zhang, J. Wang, Org. Biomol. Chem. 2013, 11, 1582-1593; a) T. Hering, D. P. Hari, B. König, J. Org. Chem. 2012, 77, 10347-10352; b) Z. Xia, O. Khaled, V. Mouriès-Mansuy, C. Ollivier, L. Fensterbank, J. Org. Chem, 2016, 81, 7182-7190; b) D. P. Hari, T. Hering, B. König, Org. Lett. 2012,14, 5334-5337; d) P. Maity, D. Kundu,B. C. Ranu, Eur. J. Org. Chem. 2015, 2015, 1727-1734; e) J. Zhang, J. Chen, X. Zhang, X. Lei, J. Org. Chem. 2014, 79, 10682-10688.

[7] L. Fensterbank, J.-P. Goddard, M. Malacria, C. Ollivier, Chimia 2012 66, 425-432.

[8] a) E. A. Merritt, B. Olofsson, Angew. Chem. Int. Ed, 2009, 48, 9052 9070; b) A. Baralle, L. Fensterbank, J. P. Goddard, C. Ollivier, Chem. Eur. J. 2013, 19, 10809-10813.

[9] a) J. Li, J. Chen, R. Sang, W.-S. Ham, M. B. Plutschack, F. Berger, S Chabbra, A. Schnegg, C. Genicot, T. Ritter, Nat. Chem. 2020, 12, 5662; b)M. H. Aukland, M.Šiaučiulis, A. West, G. J. P. Perry, D. J. Procter, Nat. Catal 2020, 3, 163-169; c) S. Donck, A. Baroudi, L. Fensterbank, J.-P. Goddard, C. Ollivier, Adv. Synth. Catal. 2013, 355, 1477-1482. For recent a review: d) Á. Péter, G. J. P. Perry, D. J. Procter, Adv. Synth. Catal. 2020, 362, 2135-2142.

[10] a) J. D. Nguyen, E. M. D'amato, M. R. Narayanam, C. R. J. Stephenson, Nature Chem. 2012, 4, 854-859; b) H. Kim, C. Lee, Angew. Chem. Int. Ed. 51, 12303-12306; c) E. H. Discekici, N. J. Treat, S. O. Poelma, K. 
M. Mattson, Z. M. Hudson, Y. D. Luo, C. J. Hawker, J. R. de Alaniz, Chem. Commun. 2015, 51, 11705-11708, d) I. Ghosh, B. König Angew. Chem. Int. Ed. 2016, 55, 7676-7679; Angew. Chem. 2016, 128 7806-7810; e) M. Majek, U. Faltermeier, B. Dick, R. Perez-Ruiz, Jacobi von Wangelin, A. Chem. Eur. Joc. 2015, 21, 15496-15501.

[11] L. Candish, M. Freitag, T. Gensch, F. Glorius, Chem. Sci. 2017, 8, 3618-3622.

[12] S. Kubosaki, H. Takeuchi, Y. Iwata, Y. Tanaka, K. Osaka, M. Yamawaki, T. Morita, Y. Yoshimi, J. Org. Chem. 2020, 85, 5362-5369.

[13] T. Morofuji, Y. Matsui, M. Ohno, G. Irakashi, N. Kano, Chem. Eur. J. 2021, 10.1002/chem.202005300.

[14] a) C. L. Frye, J. Am. Chem. Soc. 1964, 86, 3170-3171; b) G. Cerveau, C. Chuit, R. J. P. Corriu, L. Gerbier, C. Reye, J. L. Aubagnac, B. E Amrani, Int. J. Mass. Spectron Ion Phys. 1988, 82, 259-271; c) V. Corcé, C. Lévêque, C. Ollivier, L. Fensterbank, Science of Synthesis: Photocatalysis in Organic Synthesis, 2019, 427.

[15] D. Hanss, J. C. Freys, G. Bernardinelli, O. S. Wenger, Eur. J. Inorg. Chem. 2009, 2009, 4850-4859.

[16] a) C. L. Frye, J. Am. Chem. Soc. 1964, 86, 3170-3171; b) K. Lin, C. B. Kelly, M. Jouffroy, G. A. Molander, Org. Synth. 2017, 94, 16-33.

[17\} All given potentials are referenced to SCE.

[18] The structures were deposited at the Cambridge Crystallographic Data Centre with numbers 2009048 (1h); 2009049 (1d); 2009050 (1b) and can be obtained free of charge via www.ccdc.cam.ac.uk.

[19] R. J. Abraham, D. S. Ribeiro, J. Chem. Soc. Perkin. Trans. 2001, 2, 302-307.
[20] a) A. R. Bassindale, M. Sohail, P. G. Taylor, A. A. Korlyukov, D. E. Arkhipov, Chem. Commun. 2010, 46, 3274-3276, b) D. Kost, I. Kalikhman, Acc. Chem. Res. 2009, 42, 303-314.

[21] A. G. Larsen, A. H. Holm, M. Roberson, K. Daasbjerg, J. Am. Chem Soc. 2001, 123, 1723-1729.

[22] C. Lévêque, L. Chenneberg, V. Corcé, C. Ollivier, L. Fensterbank, Chem. Commun. 2016, 52, 9877-9880.

[23] J. Zhou, P.S. Mariano, Photochem. Photobiol. Sci. 2008, 7, 3936404.

[24] K. Ohkubo, K. Mizushima, R. Iwata, K. Souma, N. Suzuki, S. Fukuzumi, Chem. Commun. 2010, 46, 601-603.

[25] L. Chenneberg, C. Lévêque, V. Corcé, A. Baralle, J. P. Goddard, C. Ollivier, L. Fensterbank, Synlett 2016, 27, 731-735.

[26] a) D. Matsuoka, Y. Nishigaichi, Chem. Lett. 2015, 44, 163-165; b) Y. Nishigaichi, A. Suzuki, T. Saito, A. Takuwa, Tetrahedron Lett. 2005, 46, 5149- 5151; c) Y. Nishigaichi, A. Suzuki, A. Takuwa, Tetrahedron Lett. 2007, 48, 211-214.

[27] T. A. Halgren, J. L. Firkins, T. A. Fujimoto, H. H. Suzukawa, J. D. Roberts, Proc. Natl. Acad. SCI. USA. 1971, 68, 3216-3218.

[28] These high barrier values are reminiscent of the values found in ref. 13

[29] a) A. Kumar, M. D. Sevilla, J. Phys. Chem. B 2017, 122, 98-105; b) G. Gryn'ova, M. L. Coote, J. Am. Chem. Soc. 2013, 135, 15392-15403; c) G. Gryn'ova, D. L. Marshall, S. J. Blanksby, M. L. Coote, Nature Chemistry 2013, 5, 474-481; d) T. Kusamoto, S. Kume, H. Nishihara, J. Am. Chem. Soc. 2008, 130, 13844-13845. 
Entry for the Table of Contents (Please choose one layout)

Layout 1:

\section{FULL PAPER}

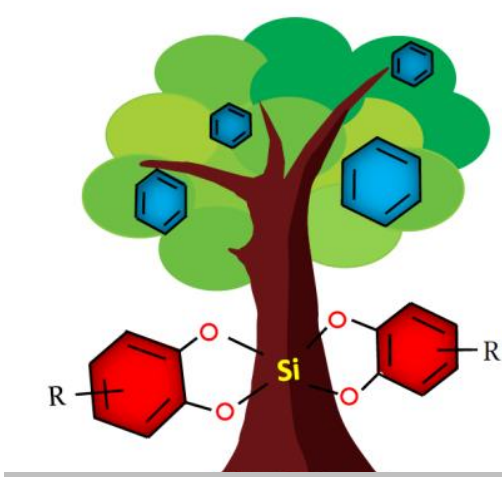

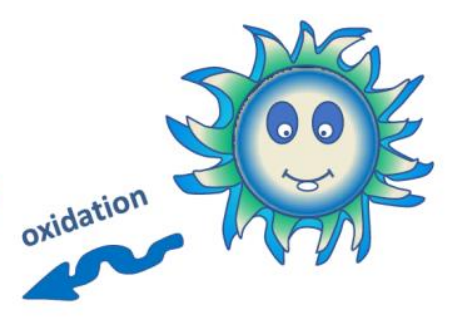

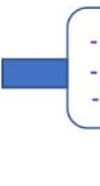

general study on phenyl silicates modification of the catechol moiety - formation of a phenyl radical
Etienne Levernier, Khaoula Jaouadi, HengRui Zhang, Vincent Corcé, Aurélie Bernard, Geoffrey Gontard, Claire Troufflard, Laurence Grimaud, Etienne Derat*, Cyril Ollivier*, Louis Fensterbank*

Page No. - Page No.

Phenyl Silicates with Substituted

While the generation of aryl radicals by photoredox catalysis is well-documented under reductive conditions, it has remained challenging under an oxidative pathway. Because of the easy photooxidation of alkyl bis-catecholato silicates, a general study on phenyl silicates bearing substituted catecholate ligands has been achieved. The newly synthesized phenyl silicates have been fully characterized and their reactivity has been explored. It was found that thanks to the substitution of the catecholate moiety and notably with the 4-cyanocatecholato ligand, the phenyl radical could be generated and trapped. Computational studies provided a rationale for these findings. 